\title{
Three new species of Phytoseius Ribaga (Acari: Phytoseiidae), and a new record from Brazil
}

\author{
PETERSON R. DEMITE ${ }^{1,4}$, ANTONIO C. LOFEGO ${ }^{2} \&$ REINALDO J.F. FERES ${ }^{2,3}$ \\ ${ }^{1}$ PPG - Biologia Animal, UNESP-Universidade Estadual Paulista, São José do Rio Preto, SP, Brazil.peterson_demite@yahoo.com.br \\ ${ }^{2}$ Depto. de Zoologia e Botânica, UNESP-Universidade Estadual Paulista, Rua Cristóvão Colombo, 2265, Jardim Nazareth, 15054- \\ 000, São José do Rio Preto, SP, Brazil \\ ${ }^{3} \mathrm{CNPq}$-Brazil Researcher \\ ${ }^{4}$ Corresponding author
}

\begin{abstract}
Three new species of phytoseiid mites (Acari: Mesostigmata), Phytoseius jurute sp. nov., Phytoseius jatoba sp. nov. and Phytoseius kaapre sp. nov., are described from native plants in northwestern São Paulo State, Brazil. In addition, Phytoseius intermedius Evans \& MacFarlane, previously known only from Asia and Africa, is recorded for the first time in Brazil. All four species were found only on plant foliage with leaf trichomes.
\end{abstract}

Key words: Predatory mites, Phytoseiinae, plumifer species group, horridus species group, Brazil

\section{Introduction}

The genus Phytoseius Ribaga includes 185 species (Chant \& McMurtry 2007), characterized within the Phytoseiinae Berlese by the retention of both setae z3 and s6 (Chant \& McMurtry 1994, 2007). Chant \& McMurtry (1994) divided the genus into three species groups distinguished by the presence/absence of setae $\mathrm{J} 2$ and R1: the horridus species group (without R1 and J2), the plumifer species group (with R1 and J2) and the purseglovei species group (with R1 only). Only ten species of the genus Phytoseius have been recorded from Brazil, nine in the plumifer group, and one in the horridus group (Moraes et al. 2004; Rosa et al. 2005). Most of those species, except for $P$. woodburyi De Leon, are known only from the Neotropical Region. In this paper, three new species of the plumifer group, P. jatoba sp. nov., P. jurute sp. nov. and $P$. kaapre sp. nov., are described, and one species of the horridus group, P. intermedius Evans \& MacFarlane, is recorded for the first time in Brazil. All the species were collected from semi-deciduous forest fragments as part of a project to survey the fauna and flora of 18 remnant forest fragments in northwestern São Paulo State, as a basis for biodiversity conservation studies.

\section{Materials and methods}

Mites were collected by examination of the leaves of host plants under a dissecting microscope. They were slide mounted in Hoyer's medium, ringed with fingernail polish, dried on a hot plate and examined under a phase-contrast microscope. Illustrations were made using a drawing tube. All measurements are given in micrometres $(\mu \mathrm{m})$; each measurement corresponds to the mean for the stated number of individuals, followed (in parentheses) by the respective range, if the measurement is variable. The holotype measurements are 